Check for updates

Cite this: J. Mater. Chem. C, 2021, 9, 16059

DOI: $10.1039 / d 1$ tc90193a

rsc.li/materials-c

\section{Kees Hummelen: a creative, inspirational and unorthodox scientist from Groningen}

\begin{abstract}
Bert Meijer (D)
To mark the occasion of the official retirement of Prof. J. C. (Kees) Hummelen, the Journal of Materials Chemistry $C$ has dedicated a special issue to honour his achievements in the field of materials chemistry. This personal essay, written by his study mate, close colleague and long-standing friend, highlights the pioneering contributions that Kees Hummelen has made in various fields of organic and materials chemistry during his 45 year long career. His research in chemistry began with asymmetric synthesis and chemiluminescence and culminated in his most notable results in the field of fullerene chemistry and the development of organic photovoltaic technology. More recently, he has also been active in the field of materials for molecular field-effect transistors, biosensors and the development of single molecule electronics based on internal $\pi$ logic. He was also a dedicated teacher and was deeply involved in societal challenges. Because of my personal relationship with Kees during all of those 45 years, I have written this essay in a somewhat unorthodox way; a way that is so characteristic of Kees.
\end{abstract}

\section{His years as a student at the University of Groningen}

The year 1971 marks Kees Hummelen's first steps in chemistry. He started his chemistry studies at the University of Groningen in the north of the Netherlands. The chemistry department had just moved

Institute for Complex Molecular Systems, Eindhoven University of Technology, P.O. Box 513, 5600 MB, Eindhoven, The Netherlands.

E-mail: e.w.meijer@tue.nl

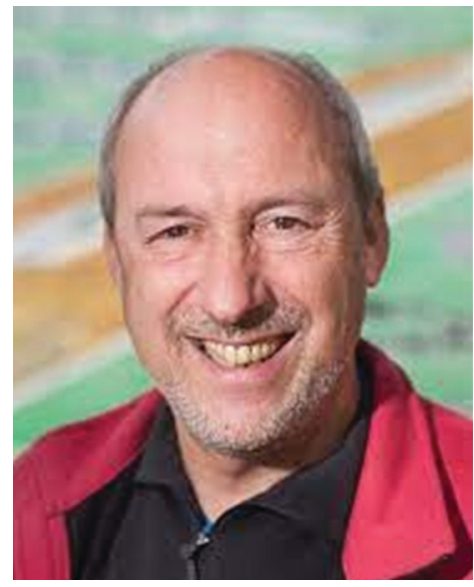

to a brand-new building on the Zernike Campus, named after the Dutch Nobel Prize winner for Physics. Without a doubt, the scientific quality of the department at that time was of the highest level in almost all disciplines. Professor Hans Wynberg had, after his return from the US, built up an outstanding Department of Organic Chemistry with seven independent research groups dealing with all major aspects of organic chemistry. It was no surprise that I met Kees in Hans Wynberg's class, as we shared our interest in molecules through the amazing and inspiring way Wynberg shared his personal excitement about the history, challenges and importance of synthetic organic chemistry. In our third year, we joined his group for our first exposure to scientific research before starting our master's. Asymmetric catalysis was the hot topic of the group at the time and we both started our experiments in this area. Whereas I failed to obtain an enantiomeric excess in the anomalous Reimer-Tiemann reaction using chiral phase-transfer catalysts, Kees was very successful in using quinine in the base-catalysed hydrogen peroxide mediated epoxidation of electron-poor olefins. ${ }^{1} \mathrm{He}$ carried out that work in close collaboration with René Helder, a postdoc in the group.
For his master's degree, Kees continued this very successful line of research using alkaloid-assisted asymmetric synthesis and a second article with him as the first author appeared in 1978. ${ }^{2}$ Although he was very successful in asymmetric catalysis during his master's, he switched to something completely different for his next step. Unlike many others, Kees is always interested in unconventional ideas.

After completing our master's degrees, both Kees and I were offered $\mathrm{PhD}$ positions in Wynberg's group. Naturally, we accepted that unique opportunity in 1978. Hans Wynberg created a vibrant chemistry group and that probably made it one of the most exciting periods in the life of the young scientist Kees Hummelen. Together with the other PhD students, including the very successful Ben Feringa and Henk Hiemstra, we enjoyed the international setting created by Wynberg. Famous chemists visited the laboratories for lectures and short visits, which stimulated this international setting - very logical now, but unique in those days - and the group tried to compete with the best groups all over the world. Although most group members worked on different topics in organic catalytic asymmetric synthesis, 
Kees and I continued the work of Joop Wieringa and Henk Numan, who synthesised respectively the first, and at that time only, stable 1,2-dioxetane, ${ }^{3}$ and its first chiral version. ${ }^{4}$

\section{His seminal contributions to chemiluminescent labels}

Kees joined the Wynberg group as a PhD student with the idea of using functionalised analogues of both stable and unstable 1,2-dioxetanes as chemiluminescent labels and probes, complementing radioactive and fluorescent probes and labels used in chemistry and biology. The first objective was the preparation of functionalised adamantylidene-1,2-dioxetanes as thermochemiluminescent labels for proteins. The term thermochemiluminescence was introduced by Kees because, apart from heat, no additional chemicals are needed to bring out the light. No dangerous radioactive compounds would be needed for immunoassays, while thermochemiluminescence would eliminate the background emissions characteristic of fluorescence. The original idea was published in 1981 as part of a conference on bioluminescence and chemiluminescence in San Diego. ${ }^{5}$ The highly stable adamantylidene-1,2-dioxetane, with an activation energy of $35.2 \mathrm{kcal} \mathrm{mol}^{-1}$ for decomposition with its emission of blue $420 \mathrm{~nm}$ chemiluminescence, was the start of the new direction of the group. Kees synthesised many new reactive 1,2dioxetanes with different reactive groups, such as $N$-hydroxysuccinimide esters to couple with antigens and antibodies. He also developed diphenylanthracene (DPA) tags to enhance the chemiluminescence of 1,2-dioxetane through energy transfer and he named his system FATIMA (an acronym for fluorescence enhanced thermochemiluminescence immunoassay). To make FATIMA practical, he selected the right solid carrier and developed a method to automatically measure the number of photons emitted. The idea was patented, and I remember our trip to New York very well. Wynberg was of the opinion that you had to be in the US for a really good patent attorney and a similar strong patent. ${ }^{6}$
Later the university sold the patent to an American company, which led to political questions in the Dutch Parliament, as the research was performed with Dutch taxpayers' money and the revenues would go to the US. The selling of the patent gave Kees - next to some private money - the great option to continue with his ideas after completing his PhD in January 1984, but also as he wanted to stay in Groningen. measure the circular polarisation in bioluminescence, because the natural 1,2-dioxetane of the firefly is also chiral. He was able to obtain firefly larvae from the US and we travelled to Leiden University to measure the possible circular polarization of the bioluminescence in the laboratories of Harry Dekkers and Peter Schippers. These larvae were activated by bathing them in amphetamine. However, they have

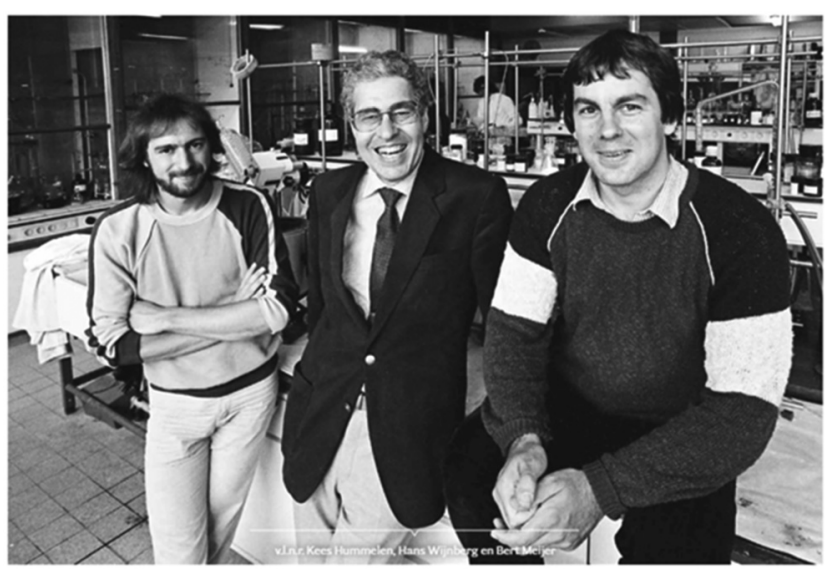

Kees (right), Professor Hans Wynberg and Bert (left) after selling their patent on chemiluminescence (1982). Copyright Geartsje J. Zondervan, used with permission.

Using chemiluminescence as a label or probe was not Kees' only contribution to science during his PhD. Together, we carried out one of our most intriguing series of experiments: our firefly project. Following the work of Henk Numan, I was interested in chiral 1,2-dioxetans and their circularly polarised chemiluminescence. In an attempt to use these 1,2-dioxetanes, I also synthesized molecules that were chiral only in the presence of an ${ }^{18} \mathrm{O}$-isotope ${ }^{7}$ or a ketone in its excited state. ${ }^{8}$ But Hans Wynberg had the idea that it should be possible to
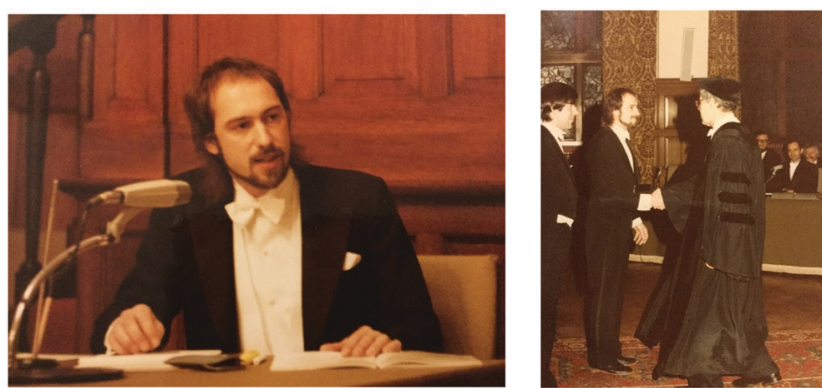

Kees defending his PhD research (left) and being congratulated by Professor Hans Wynberg with his Doctoral degree after the official defence in 1985 (right) with me as his assistant. Copyright Geartsje J. Zondervan, used with permission. 
In January 1984, Kees graduated summa cum laude, with a thesis entitled "Inherently chemiluminescent compounds as new labels in clinical analysis" and he continued his research to further improve and develop the idea of thermochemiluminescence and FATIMA. ${ }^{10} \mathrm{He}$ did this together with Theo Luider, Jan Koek and Dré Oudman in Wynberg's group. With this approach, many assays were developed, including the measurement of low concentrations of hormones, tumour markers and some proteins. The chemiluminescence research in the Wynberg group ended not long after the doctoral defence of Theo Luider in $1988 .{ }^{11}$ However, it was not the end of the use of chemiluminescence in biological labels and probes. In particular, A. Paul Schaap from Wayne State University picked up the idea and modified the system in an elegant way and brought it to the commercial market. Schaap was already active in 1,2-dioxetane chemistry during his PhD with Paul Bartlett at Harvard and, probably inspired by Kees' work, he also extended his work to labels and probes and wrote many patents and articles on modified 1,2-dioxetanes in the years 1995-2001. ${ }^{12,13}$ Schaap founded Lumigen Inc., which became a very successful company in the use of less stable and triggered dialkyl-substituted 1,2-dioxetanes; structures that were closely related to my doctoral work. ${ }^{14}$ Today, Doron Shabat in Tel Aviv is the leading scientist in using chemiluminescence in a biomedical setting. ${ }^{15}$

\section{His musical years}

Although Kees and Wynberg enjoyed the many activities to bring FATIMA and the thermochemiluminescence labels to the clinic, the special position of Kees ended as the grants were finishing and the University did not offer him a tenure position. It was time for a sabbatical and Kees decided to say goodbye to chemistry for the time being and focussed on his second passion.

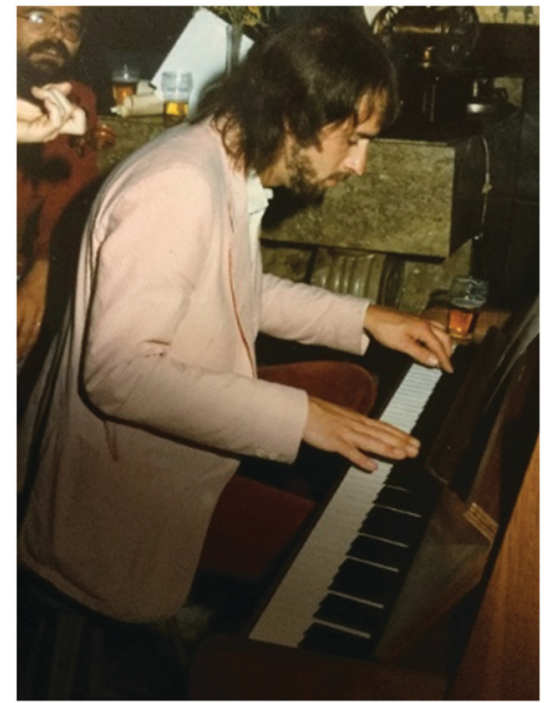

Kees playing piano in the early eighties. Copyright Geartsje J. Zondervan, used with permission.

For as long as I have known him, Kees has been a very talented piano player, with a preference for jazz music. $\mathrm{He}$ always combined his study and research with music and played at the party of my PhD defence, as well as my wedding. He became a full-time artist in the years 1989-1993. Somehow, he followed the path of Albert Alberts, another PhD student with Wynberg. Albert combined science with playing saxophone during his whole career, where he played in his own band "AA and the Doctors". Kees really did it for his hobby, but played in many concerts and parties in Groningen and beyond. The bands he played in had beautiful names like "Bas \& the Boomerangs", "Wechflash" and "Hummelen, Sulman and van Strien". He also combined playing the piano with supporting his stepdaughter Nathalie as her production manager in making art video productions and movies for Pavlov Medialab in The Netherlands. After his sabbatical as an artist, his strong passion for chemistry brought him back to science and, with the help of Hans Wynberg, he was introduced to Fred Wudl at the University of California in Santa Barbara (UCSB). Probably not many scientists would take the risk of having someone that has been out of science for 4 years as a postdoc. However, not the world-famous Fred Wudl: he offered Kees a postdoc position and in the summer of 1993 Kees moved to the US and the sunny beaches of California.

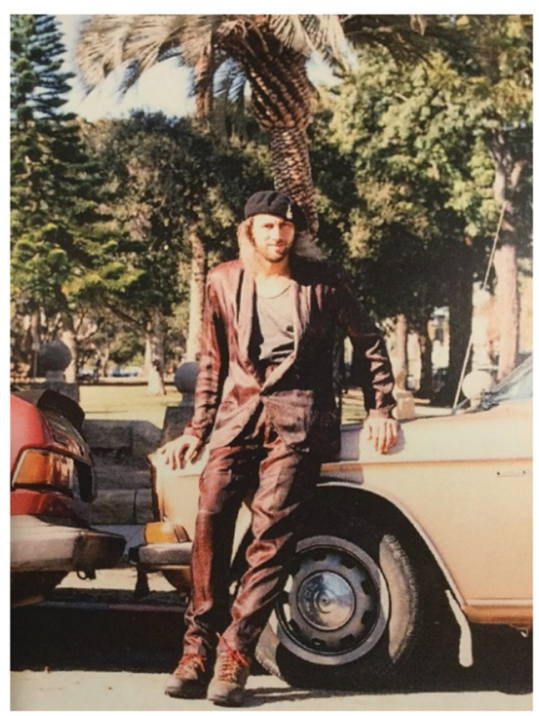

Kees as a postdoc in Santa Barbara after 4 years of being an artist. Copyright Geartsje J. Zondervan, used with permission.

\section{His period as a postdoc at the University of California in Santa Barbara}

Kees spent two very successful years as a post-doctoral fellow with Fred Wudl at the Institute for Polymers and Organic Solids at UCSB in Santa Barbara, California. Fred Wudl joined UCSB after his period as a research scientist at the famous Bell Labs in New Jersey. His group was active in the synthesis and characterisation of new conjugated polymers and published many fascinating papers, often together with Alan Heeger. As one of the most creative synthetic chemists, Wudl recognised the potential of $\mathrm{C}_{60}$ chemistry. His group was one of the first synthetic groups to discover the many fascinating properties of Buckminsterfullerene, or buckyball for short. As a creative chemist who likes to think outof-the-box, Kees joined this journey to synthesise functional buckyballs; a research topic that perfectly fits Kees' desire to work on untrodden paths. His first paper from Santa Barbara was with my Eindhoven colleague René Janssen, who was a visiting scientist at UCSB at 
that time. They reported the photochemical conversion of fullerene to methanofullerene via the Zimmerman rearrangement. ${ }^{16}$ Although the target of the new $\mathrm{C}_{60}$ molecules was related to overcoming HIV infection, many unknown and highly interesting physical properties were discovered. The real breakthrough for Kees and his research came with his synthesis of phenyl- $\mathrm{C}_{61}$ butyric acid methyl ester, better known as $\left[\mathrm{C}_{60}\right]$-PCBM. ${ }^{17}$ This new $\mathrm{C}_{60}$ derivative turned out to be a wonderful electron acceptor in mixtures of $\pi$-conjugated polymers and the first polymer bulkheterojunction photovoltaic device was born. This seminal work was carried out with the close cooperation between the groups of Wudl and Heeger and appeared as a highly cited article in Science. ${ }^{18}$ And in one year, the piano player Kees Hummelen became a wellknown materials chemist. Many original articles appeared as the result of his postdoc period at UCSB. From this period, which I only followed from a distance, it is impossible to make a fair selection from the many and exceptional research achievements that Kees has worked on or contributed to. To mention only a few, I first come to a paper in JACS that I always must think of when I need a title for one of our papers. He published, together with Maurizio Prato and Fred Wudl, the first step towards controlling the opening of an $\mathrm{C}_{60}$ molecule and perhaps using it as a guest-host system. It was published with the beautiful title "There is a hole in my bucky". ${ }^{19}$ It was followed later by a joint paper with our group on the resolution and circular dichroism of an asymmetrically cage-opened $\mathrm{C}_{60}$-derivative. ${ }^{20}$ Another example comes from the close cooperation with his friend Serdar Sariciftci, where they studied in detail the enhanced nonlinear absorption and optical limiting in semiconducting polymer/methanofullerene charge transfer films. ${ }^{21}$ However successful his position in Santa Barbara was, he missed his home and friends in Groningen and in 1995 he wanted to return to the Netherlands. With a wealth of new knowledge and as a rising star in materials chemistry, he had the strong will to continue with this societally very relevant research theme. But how? With the hope to get an answer, Kees approached me.

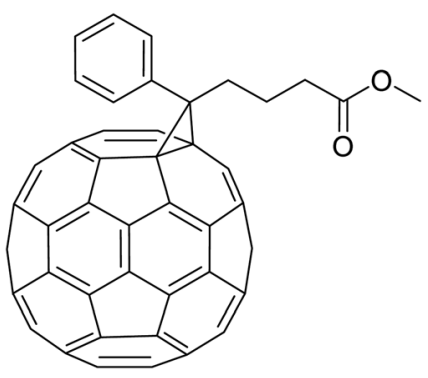

The famous $C_{60}-P C B M$ that was introduced and synthesized by Kees.

\section{His return to the Netherlands and the start of photovoltaic research in the Netherlands}

After my PhD in June 1982 and research positions in the laboratories of Philips Research and DSM Research, I started as a professor in Eindhoven in 1991. Of course, I followed Kees' fascinating research in Santa Barbara and saw him shine with his important contributions to the first real polymer-based photovoltaic cells with their network of internal donor-acceptor heterojunctions. After a nice conversation and his wish to come back to the Netherlands, we agreed that he would start working as a senior postdoc in our group for half a year. In this way, he could find out what options were available to work on his dream to make the Netherlands an important player in alternative energy. It was great to have Kees with us and he enjoyed it very much, even though we were not active in solar cells. But he could further strengthen his collaborations with René Janssen, who, inspired by his stay in Santa Barbara, also became a leading scientist in polymer photovoltaics. It is illustrative of Kees that he never complained about doing something totally different as he always comes with an interesting approach to any topic that is presented to him. And indeed, he made some great discoveries in our dendrimer research, a field in-between organic and polymer chemistry. The most impactful analysis Kees did, together with Joost van Dongen, was using electrospray mass spectrometry to analyse the purity of dendrimers. In our research, we always used poly(propylene imine) dendrimers as the starting building block and Kees brought the problem of the purity or polydispersity of dendrimers to the fore. ${ }^{22}$

But the most important event of his stay with us was his acquaintance with the Netherlands Organisation for Energy and Environment. He asked them to seriously invest in polymeric photovoltaics based on bulk-heterojunctions. Why was Kees successful in convincing them? He told the Organisation that the three key players of the pioneering activities in Santa Barbara were now in Europe; Serdar Sariciftci went to Austria and René Janssen and Kees were back in the Netherlands. In other words, Europe, and especially the Netherlands, could play a central role in this area of research that is so important for a sustainable society. Kees is indeed a great communicator and can inspire many people to follow him and his ideas - ideas that always have a new aspect that nobody has thought of but that are often considered very attractive to start with. A large grant was given to Kees as the main applicant and with that support he could return to Groningen, where he was appointed associate professor in 1998, followed by his promotion to full professor in chemistry in 2000 and where he stayed until his retirement.

\section{His successful career as a professor in Groningen}

Fifteen special and unorthodox years separated Kees' PhD from his honourable and well-deserved promotion to full professor in Groningen. From a wild but successful student with many experiences of an exciting life to live, Kees could now inspire many young people as a leading scientist in one of the most important research themes for a sustainable society; a subject that many people love. In the beginning, Kees was completely focused on solar cells and later he broadened his interest to many other devices related to molecular electronics. However, his love affair with $\mathrm{C}_{60}$ chemistry, especially 
with all of the derivatives of $\mathrm{C}_{60}$-PCBM, is overwhelming and has dominated most of his research. He even started a synthetic company for these $\mathrm{C}_{60}$-derivatives and, in this way, made these molecules available to many groups and companies around the world. Later, he was even able to start the cosmetics company Combray, in which he sells a revolutionary skin care product containing Oxofulleram, a new and multipatented antioxidant. While I can only guess at the molecules used by the company, the name Oxofulleram tells us that the antioxidant is most likely a $\mathrm{C}_{60}$ derivative. Driven by beauty; proven by science is Combray's slogan. ${ }^{23}$ This is all based on his deep insight into all aspects of the properties and functions of buckyballs.

In an eye-catching paper in Advanced Energy Materials, Kees, together with Jan-Anton Koster and Sean Shaheen, introduced three pathways to a new efficiency regime for organic solar cells. They elucidated the important role of the absorption of charge-transfer states. When this absorption is sufficiently weak, they proposed that organic solar dielectric constants are beneficial. However, the design of molecular semiconductors with such high dielectric constants is far from trivial, but that is a real challenge fitting perfectly with the research attitude of Kees; nothing is impossible, only when you do not try it. In 2020, he published a $\mathrm{C}_{60}$-PCBM substituted with two ethylene glycol chains and reached a double-digit dielectric constant with fullerene derivatives. ${ }^{25}$ More recently, others have discussed the topic of band gap engineering in blended organic semiconductor films based on dielectric interactions and cited the ideas of Kees. ${ }^{26}$

During his short stay in Eindhoven and the joint research grant with René Janssen, many studies were carried out combining the know-how of both laboratories. One of my favourites is his study of the supramolecular arrays of fullerenes by quadruple hydrogen bonding. It was his and Luis Sanchez's introduction to supramolecular polymers (structure 1 in the figure below) and it became a research topic that turned Sanchez from a postdoc at Kees into a leading chemist in all aspects of supramolecular polymers. ${ }^{27,28}$

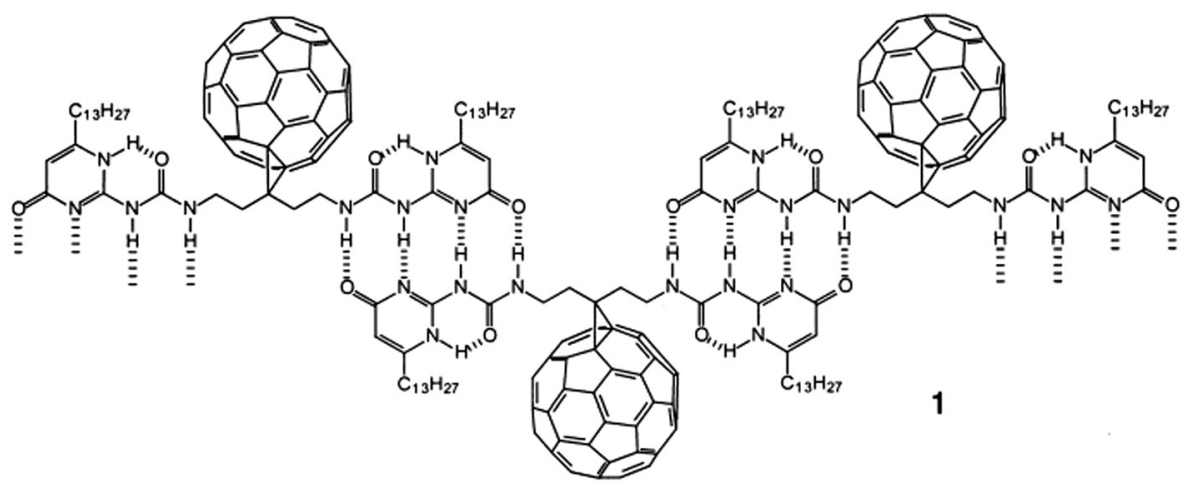

Combining supramolecular polymers and $C_{60}$-chemistry.

cells could become real competitors of inorganic ones, used today throughout the world. ${ }^{24}$ In that article, they proposed the use of organic semiconductors with high dielectric constants. The low dielectric constants of common organic materials means that excitation by light produces excitons, i.e. bound electronhole pairs, rather than free charges. To lower this binding energy, organic semiconductor materials with very high
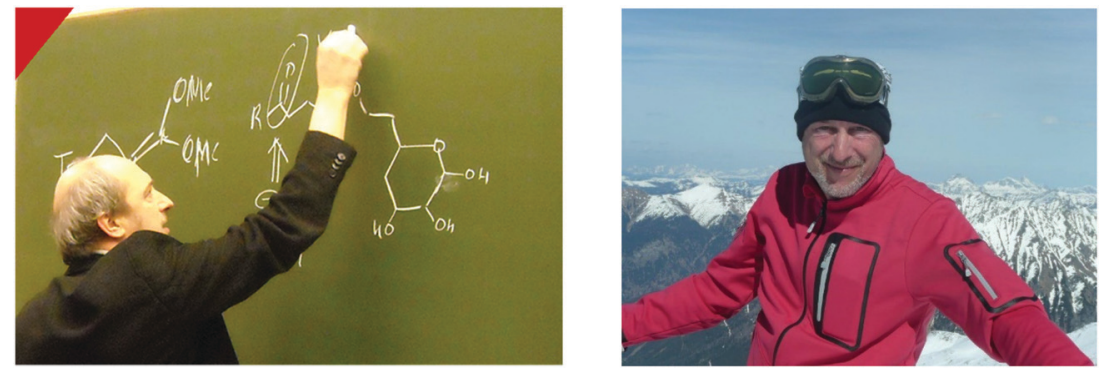

Kees enjoying teaching undergraduate students (left) and skiing in the mountains (right). Copyright Geartsje J. Zondervan, used with permission.
For the last twelve years, his main research activities have been in fullerene chemistry and the development of polymer photovoltaic technology. Other, more recent research topics in the field of molecular electronics are materials for molecular field effect transistors, biosensors and the development of single-molecule electronics, based on internal $\pi$-logic. As an example, I like to give here his ideas about so-called omniconjugation. It is a real Kees Hummelen research idea and is based on molecules with linear $\pi$-conjugated pathways between all substituents. These molecules have in common that they interconnect many molecules in a molecular electronic circuit. ${ }^{29}$ I am afraid that we will have to wait and see if it becomes a success story.

Besides his passion for new chemical challenges in general and for material chemistry for (opto)electronic devices in particular, Kees is also fully committed to education. From the moment he returned to Groningen in 1998, he has enjoyed teaching the younger generations. And it must be a real pleasure to attend his inspirational lectures in which he combines basic chemistry with important recent findings. Through the years, he has optimized his teaching and he was very often nominated as Teacher of the Year and received this prestigious award twice. 


\section{His next steps in life}

As befits a scientist, Kees has thrown himself wholeheartedly into the social discussions on green energy. Through many public lectures for schools and radio appearances, he has made it clear that climate change really must come to a halt and that solar cells may be the best solution. Along with the well-known silicon-based solar cells, flexible polymerbased cells would be a welcome addition. It should therefore come as no surprise that the small village of Oostwold - west of the city of Groningen where Kees now lives with his partner Geartsje Zondervan - has made a major investment in a 1.6-hectare solar park. This solar park is the first project of the cooperation of which is Kees one of the board members. After realising this project on a landfill, Kees will spend his time on an even bigger project called “Zonnewal”. Kees retired from the University of Groningen and will enjoy life together with Geartsje and all of his activities, of which skiing in the mountains is one of the hobbies he likes to do. Although his contributions to science will decrease, his legacy will continue for a long time and many colleagues and students will keep in touch with Kees. Of course, we all thank him for his many contributions to science and wish him a long and enjoyable retirement.

\section{Acknowledgements}

Photographs provided by Geartsje J. Zondervan and used with permission. Please contact the author for further details.

\section{References}

1 R. Helder, J. C. Hummelen, R. W. P. M. Laane, J. S. Wieringa and H. Wynberg, Tetrahedron Lett., 1976, 17, 1831-1834.

2 J. C. Hummelen and H. Wynberg, Tetrahedron Lett., 1978, 19, 1089-1092.
3 J. H. Wieringa, J. Strating, H. Wynberg and W. Adam, Tetrahedron Lett., 1972, 13, 169-172.

$4 \mathrm{H}$. Wynberg and H. Numan, J. Am. Chem. Soc., 1977, 99, 603-605.

5 H. Wynberg, E. W. Meijer and J. C. Hummelen, Methods Enzymol., 1981, 57, 687-689.

6 J. C. Hummelen, E. W. Meijer and H. Wynberg, US Pat., 4705847, 1987.

7 E. W. Meijer and H. Wynberg, J. Am. Chem. Soc., 1982, 104, 1145-1146.

8 E. W. Meijer and H. Wynberg, Angew. Chem., 1988, 100, 1004-1005.

9 H. Wynberg, E. W. Meijer, J. C. Hummelen, H. P. J. M. Dekkers, P. H. Schippers and A. D. Carlson, Nature, 1980, 286, 641-642.

$10 \mathrm{~J}$. C. Hummelen, Inherently chemiluminescent compounds as new labels in clinical analysis, $\mathrm{PhD}$ thesis, University of Groningen, 1984.

11 T. M. Luider, Thermochemiluminescence and its applications in immunoassay, PhD thesis, University of Groningen, 1988.

12 A. P. Schaap, T.-S. Chen, R. S. Handley, R. DeSilva and B. P. Giri, Tetrahedron Lett., 1987, 28, 1155-1158.

13 A. P. Schaap and H. Akhavan-Tafti, US Pat., 5892064-A, 1999.

14 E. W. Meijer, Chemiluminescence in Action; synthesis, characterization, and applications of 1,2-dioxetanes, $\mathrm{PhD}$ thesis, University of Groningen, 1982.

15 J. I. Scott, S. Gutkin, O. Green, E. J. Thompson, T. Kitamura, D. Shabat and M. Vendrell, Angew. Chem., 2021, 133, 5763-5767.

16 R. A. J. Janssen, J. C. Hummelen and F. Wudl, J. Am. Chem. Soc., 1995, 117, 544-545.

17 J. C. Hummelen, B. W. Knight, F. Lepeq, F. Wudl, J. Yao and C. L. Wilkins, J. Org: Chem., 1995, 60, 532-538.
18 G. Yu, J. Gao, J. C. Hummelen, F. Wudl and A. J. Heeger, Science, 1995, 270, 1789-1791.

19 J. C. Hummelen, M. Prato and F. Wudl, J. Am. Chem. Soc., 1995, 117, 7003-7004.

20 J. C. Hummelen, M. Keshavarzk, J. L. J. van Dongen, R. A. J. Janssen, E. W. Meijer and F. Wudl, Chem. Commun., 1998, 281-282.

21 M. Cha, N. S. Sariciftci, A. J. Heeger, J. C. Hummelen and F. Wudl, Appl. Phys. Lett., 1995, 67, 3850-3852.

22 J. C. Hummelen, J. L. J. van Dongen and E. W. Meijer, Chem. - Eur. J., 1997, 3, 1489-1493.

23 www.combray-skincare.com/nl.

24 L. J. A. Koster, S. E. Shaheen and J. C. Hummelen, Adv. Energy Mater., 2012, 2, 1246-1253.

25 S. Rousseva, H. den Besten, F. S. van Kooij, E. L. Doting, N. Y. Doumon, E. Douvogianni, L. J. A. Koster and J. C. Hummelen, J. Phys. Chem. C, 2020, 124, 8633-8638.

26 K. Ortstein, S. Hutsch, M. Hambsch, K. Tvingstedt, B. Wegner, J. Benduhn, J. Kublitski, M. Schwarze, S. Schellhammer, F. Talnack, A. Vogt, P. Bäuerle, N. Koch, S. C. B. Mannsfeld, H. Kleemann, F. Ortmann and K. Leo, Nat. Mater., 2021, DOI: 10.1038/ s41563-021-01025-z.

27 L. Sánchez, M. T. Rispens and J. C. Hummelen, Angew. Chem., Int. Ed., 2002, 41, 838-840.

28 M. T. Rispens, L. Sánchez, E. H. A. Beckers, P. A. van Hal, A. P. H. J. Schenning, A. El-ghayoury, E. Peeters, E. W. Meijer, R. A. J. Janssen and J. C. Hummelen, Synth. Met., 2003, 135-136, 801-803.

29 M. H. van der Veen, M. T. Rispens, H. T. Jonkman and J. C. Hummelen, Adv. Funct. Mater., 2004, 3, 215-223. 